\title{
Growth stimulating effect of bovine milk lactoferrin on dermal cells and probiotic bacteria
}

\author{
Evgeniy Ivanovich Titov', Natali Aleksandrovna Tikhomirova', Inna Isaakovna Ionova', \\ Ivan Fiodorovich Gorlov ${ }^{2,3 *}$, Marina Ivanovna Slozhenkina ${ }^{2,3}$, Natali Ivanovna Mosolova ${ }^{2}$, Elena Yurievna Zlobina ${ }^{2}$ \\ ${ }^{1}$ Moscow State University of Food Production, 125080, 11, Volokolamskoye Shosse, Moscow, Russia, ${ }^{2}$ Volga Region Research Institute of \\ Manufacture and Processing of Meat-and-milk Production, Rokossovskogo Street, 400131, 6, Volgograd, Russian Federation, ${ }^{3}$ Volgograd \\ State Technical University, 400005, 28, Lenina avenue, Volgograd, Russia
}

\section{A B S T R A C T}

\begin{abstract}
The purpose of this work was to solve the regulation problems of protection processes through biologically active proteins in the animal body, in particular, to study the role of the receptor mechanism in the effect of lactoferrin and its derivatives (peptides) on the cell proliferation. There are presented the results of studying the bovine milk lactoferrin effect on the dermal fibroblasts and human keratinocytes, the growth of Bifidobacterium adolescentis B-1, as well as the study of anti-ulcer and dysbacteriosis activity of bovine milk lactoferrin and its hydrolyzates in an experiment in vivo. Bovine milk lactoferrin in the same dose inhibits the keratinocytes proliferation much more actively than stimulates the proliferation of dermal fibroblasts that allowed considering the immortalized keratinocytes as targets in a model system with bovine lactoferrin to study the mechanism inhibiting the cell growth. The bifidobacteria strains, which are not sensitive to bovine lactoferrin, turned out to be inert toward its peptides that may indicate the possibility of implementing the action on the cellular target of bovine lactoferrin and products of its limited proteolysis through a single receptor mechanism. Peptides of bovine lactoferrin, the most active in reference to stimulating the bifidogenic property of beneficial microorganisms, proved to be more effective in protection the gastrointestinal tract from ulceration of the gastric mucosa and dysbiosis. The minimum dose (1 mg per $1 \mathrm{~kg}$ of the animal body weight), the mucosal ulcerous erosion was not diagnosed as a result of injecting the mixture, was $\sim 300 \mathrm{mg}$ for bovine milk lactoferrin, $\sim 100 \mathrm{mg}$ for hydrolysates (after 4 hours of proteolysis), and $\sim 10 \mathrm{mg}$ (after 24 hours of proteolysis). In the experiments in vitro and in vivo, the peptides of low molecular weight have a stronger biological effect than the native bovine lactoferrin in the same concentration.
\end{abstract}

Keywords: Antidysbiosis activity; Antiulcer activity; Bovine milk lactoferrin; Cell proliferation; Wistar rat

\section{INTRODUCTION}

Therapeutic capabilities of bovine lactoferrin (bLF) allow us to consider it as an active basis for medical preparations and therapeutic food products (Yoo et al., 1997; Fotschki et al., 2015; García-Tejedor et al., 2015a and 2015b; Ke et al., 2015). Currently, in the Russian Federation there is a perspective to solve the problem of domestic production of bLF by intensive growth of waste-free processing of raw milk through the implementation of innovative developments, especially baromembrane and nanotechnologies (Khramtsov, 2010 and 2015).

The protective function of milk is known to be largely due to the presence of serum proteins in its composition where bLF plays a special role as a control growth factor and has antimicrobial, bifidogenic, antioxidant, anti- inflammatory, and immune-correcting activity (Kim et al., 2004; Yamauchi et al., 2006; Rahman et al., 2008 and 2009; Hayakawa et al., 2009; Jenssen and Hancock, 2009; Montiel et al., 2015). Bovine lactoferrin is effective against such dangerous microorganisms like Streptococcus spp., Vibrio cholerae, Helicobacter pylori (Mario et al., 2003; Okuda et al., 2005; Sachdeva and Nagpal, 2009). It also resists a rather rare but very dangerous disease - listeriosis, leading to such consequences as the prenatal fetal death, malformations of newborns, children after listeria meningitis often suffer from paralysis and mental retardation (Ripolles et al., 2015). Bovine lactoferrin has bacteriostatic and bactericidal effect. Bovine lactoferrin exhibits its bacteriostatic effect when binds iron ions, depriving the bacteria of the element necessary for their growth and activity. The bactericidal action of bLF is based on binding to lipopolysaccharides, the main components of the bacterial walls, with a process

\footnotetext{
${ }^{*}$ Corresponding author:

Ivan F. Gorlov, Volga Region Research Institute of Meat-and-milk Manufacture and Processing, 400131, Rokossovskogo St., 6, Volgograd, Russia. Tel.: +78442391101. Fax.: +78442391142. E-mail: niimmp@mail.ru.
} 
destructive for the cell membrane to start: A bacterium without coat, unable to withstand the external pressure, "bursts". This resembles the operating principle of antibiotics, but the drug-induced antimicrobial agents $\varnothing$ damage both the bacteria and the cells of the human body. Antimicrobials also cause the death of beneficial microflora. Intestinal dysbiosis develops, the digestibility of nutrients, vitamins, trace elements decreases, the immune protection weakens, as large number of immunocompetent cells are killed at struggle with microbes. Bovine lactoferrin is free of such deficiencies.

Due to the bovine lactoferrin's multifunctionality aimed at maintaining homeostasis of a living body, it has recently attracted attention of researchers. Furthermore, analysis of the data suggests that bLF refers to a group of proteins that regulate receptor mechanism for implementing many cellular processes, including proliferation of both animal and microbial cells, and especially of the cells of beneficial intestinal microflora (Legrand et al., 2008; Tomita et al., 2009). At the same time, the problems of the structural and functional role of the receptors, their affinity activity against the proliferation inducing factor, the signal passage in the cell have not been learned that determines the relevance of further research. The choice of an adequate model of the cell target, which regulates the cell proliferation through the receptor mechanism of the factor, is of particular importance in the experiment planning. Given that the up-to-date sector in the surgical transplantation is the search for new natural growth regulators of cells and human tissues in vitro, the study of the bLF applicability in this field of knowledge has been of special significance. Taking into account the above factors, the team of authors set the task to study the effect of bLF, isolated from cow's milk, on dermal fibroblasts and human keratinocytes. The bLF Peptides, the most active in reference to stimulating the bifidogenic property of beneficial microorganisms, proved to be more effective in protection the GI tract from ulceration of the gastric mucosa and dysbiosis.

The purpose of this work was to solve the regulation problems of protection processes through biologically active proteins in the animal body, in particular, to study the role of the receptor mechanism in the effect of lactoferrin and its derivatives (peptides) on the cell proliferation.

\section{MATERIALS AND METHODS}

\section{Preparation and identification of bLF}

Due to the fact that bLF is contained in the milk in considerable amounts (the highest concentration is found in colostrum: In the female - up to $6 \mathrm{~g} / \mathrm{l}$, in the cow - up to $300 \mathrm{mg} / \mathrm{l}$ ), in our studies, bLF was isolated from cow milk and purified by the ion exchange chromatography using cation exchanger Macro-Prep HQ Support (Bio-Rad Laboratories Inc., USA). The resin washed with distilled water was placed into in a potassium phosphate buffer (0.05M, pH 6.7) with constant stirring for 1.5 hours to charge the functional groups. Then, the charged ion exchanger was separated from the buffer and placed in the skim milk (Zhao et al., 2015). It was left with constant stirring at $4 \pm 2^{\circ} \mathrm{C}$ for 24 hours. The exchanger with bound protein was separated by decantation and washed with potassium phosphate buffer $(0.05 \mathrm{M}, \mathrm{pH} 6.7)$. The resin was packed into column by gravity. Elution of proteins was performed by potassium phosphate buffer $(0.05 \mathrm{M}$, $\mathrm{pH}$ 6.7) with concentration gradient of $\mathrm{NaCl}(0.1-1.0 \mathrm{M})$ at a flow rate of $1.5 \mathrm{ml} / \mathrm{min}$. The isolated protein fractions with the absorbance value more than 0.1 (at $280 \mathrm{~nm}$ ) were dialyzed through a semipermeable membrane against distilled water at $4 \pm 2^{\circ} \mathrm{C}$ for 24 hours. The identification of bLF was carried out by the methods of iron-binding capacity determination, electrophoresis, enzyme-linked immunosorbent assay (ELISA). The amount of bLF in chromatographic fractions was determined by ELISA (competitive option) based on polyclonal antibodies (Fotschki et al., 2015). The iron-binding capacity was assessed by saturating capacity of protein with ferric iron in the presence of carbonate ions. Change of bLF into apo- and holo-form was achieved by dialysis of its solutions against citric acid ( $\mathrm{pH}$ 2), and iron carbonate, respectively (Shimazaki, 2000). The iron saturation degree of the protein was determined spectrophotometrically according to the color change at $465 \mathrm{~nm}$ (Shimazaki et al., 1998). Electrophoresis was performed by Laemmli method (Laemmli, 1970).

For comparison, some experiments were carried out using commercially available bLF (Sigma, USA).

\section{Proteolysis of bLF}

Proteolysis of bLF was performed with porcine pepsin (Sigma, USA) at a concentration of $\omega / \omega$ of the substrate $3 \%$ at $37^{\circ} \mathrm{C}$, pH 2.5 (Tomita et al., 1991; Ripolles et al., 2015). The reaction was stopped by heating the mixture for 15 minutes at $80^{\circ} \mathrm{C}$. The neutralization of the reaction mixture was carried out with $\mathrm{NaOH}(1 \mathrm{~N})$. Then, the mixture was centrifuged for $15 \mathrm{~min}$ at $15000 \mathrm{~g}$. The supernatant was analyzed electrophoretically. Hydrolyzate powders were prepared by freeze-drying the supernatant after dialysis through a semipermeable membrane against distilled water.

\section{Culturing the human cells}

The research was conducted on two lines of human cells: Immortalized human keratinocytes ( $\mathrm{HaCaT}$ ) and human dermal fibroblasts. Prior to the experiment, the cells were stored frozen. After thawing, they were cultured in Dulbecco's Modified Eagle's Medium (DMEM) 
supplemented with 10\% Fetal Bovine Serum (FBS, PAA Laboratories, Austria), $4 \mathrm{mM}$ L-glutamine at $37^{\circ} \mathrm{C}$ in a $\mathrm{CO}_{2}$-incubator. The medium change was carried out every 1-2 days. When the culture reached the confluence layer, the cells were passaged to 96-well plate at a concentration of 30 thous. cells $/ \mathrm{ml}, 200 \mu \mathrm{L}$ to each of the wells. After the cells attached, the medium was changed to fresh one supplemented with serum free bLF or bLF with $10 \%$ FBS.

The bLF doses made 50,100, and $200 \mathrm{~g} / \mathrm{ml}$. After four days, the MTT'-test was performed. The matrix solution of MTT (Sigma, USA) was added to each well of the 96-well plate at a ratio of 1:10 in relation to the volume of the growth medium, incubated in a $\mathrm{CO}_{2}$-incubator for $3-4$ hours at $37^{\circ} \mathrm{C}$ and $5 \% \mathrm{CO}_{2}$. After incubation, the liquid was removed from the wells carefully so as not to damage the formed formazan crystals, insoluble in the aqueous medium. Each well was added with $100 \mu \mathrm{L}$ of dimethyl sulfoxide (DMSO) to dissolve the crystals, and then carefully pipetted until homogeneous staining. The absorbance was counted in ABS mode on a tablet spectrophotometer using a filter of $540-590 \mathrm{~nm}$ as the main one, and a filter of $630-690 \mathrm{~nm}$ as a correcting one. All tests were performed in seven parallel replicates.

\section{Culturing the microorganisms}

Standard microbiological techniques were applied: Counting the number of colonies on nutrient agar in Petri dishes (Colony Forming Unit-CFU) and determination of the optical density of the cell suspension in nutrient broth at $620 \mathrm{~nm}$. The bLF hydrolysates intended for studying their influence on the cells under study in model experiments were prepared by proteolysis using porcine pepsin.

\section{Studying the ulcer lesions of the gastric mucosa of rats} The study was conducted on white male rats of the "Wistar" line weighing 180-200 g. The animals were kept under standard vivarium conditions with free access to food and water. One day prior to experimentation, the rats were deprived of food, and 3 hours before the experiment - of water. Ulcer lesions in gastric mucosa of the animals were induced with mixture of hydrochloric acid $(100 \mathrm{mM})$ and ethanol $(80 \%)$. Thirty minutes before inducing the lesions, normal saline supplemented with bLF in various concentrations or its proteolysis products as protective agents was introduced into the stomach. The ulcer index, an integral length indicator of the necrotic lesions formed in the gastric mucosa, was calculated.

Experiments on rats were performed in accordance with International guiding principles for biomedical research involving animals, developed by the Council for International Organizations of Medical Sciences (CIOMS, 1985) and Guide for the care and use of laboratory animals (2011).

\section{RESULTS AND DISCUSSION}

As Fig. 1 shows, in the process of elution, proteins emerged from the chromatography column in two peaks. According to the analysis, the first peak corresponds to lactoperoxidase (LP). In the protein fraction of the second peak the LP activity was absent. On electrophoregram, protein of the second peak gave one clear line of protein corresponding to the molecular weight of $78 \mathrm{kDa}$. This protein was identified by ELISA as bLF. Its nativeness was proved by full maintenance of iron-binding capacity. The value of absorbance at wavelength $465 / 280 \mathrm{~nm}$ for the holo-form saturated with ferric iron coincides with the value of bLF for commercial products.

The effect of bLF on the cell growth was registered under the conditions without adding into culture medium and using FBS as a growth factor at a dosage range of

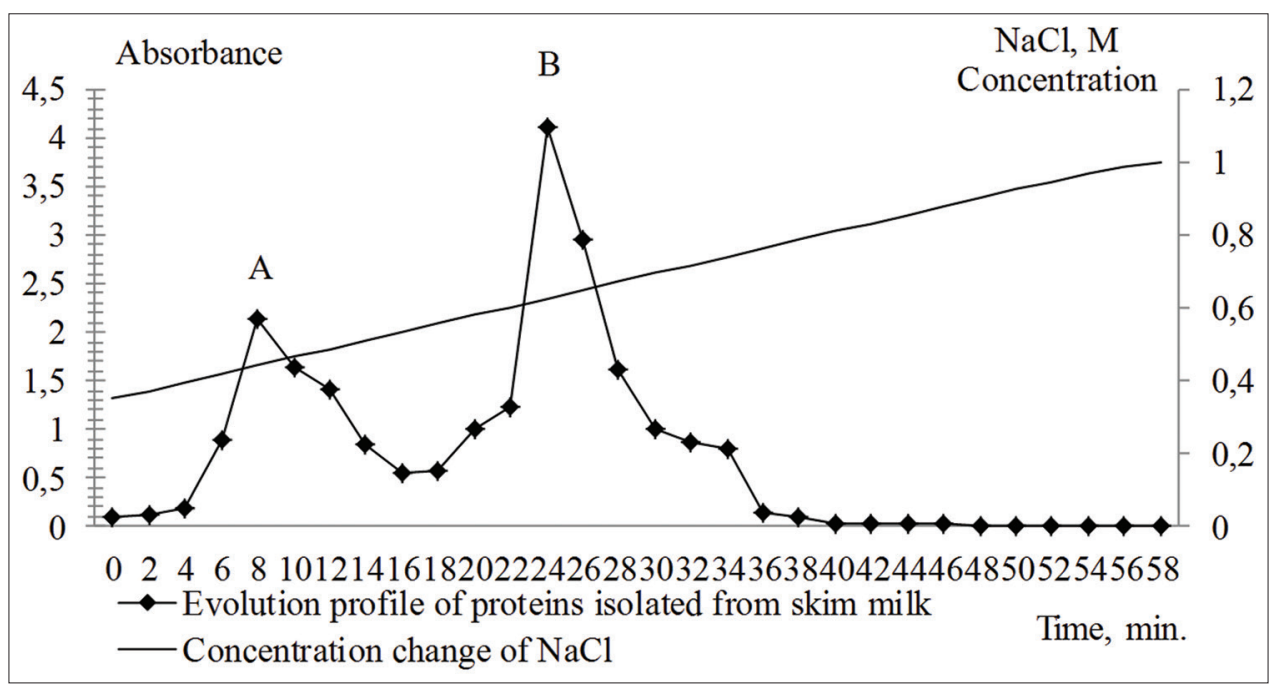

Fig 1. Chromatographic purification of bovine lactoferrin: (A) lactoperoxidase; (B) bovine lactoferrin. ${ }^{c} P<0.05$ (in comparison with control). 
$50-200 \mu \mathrm{g} / \mathrm{ml}$ for both cell types. So, there was observed a stimulation of fibroblasts and pronounced inhibition of keratinocytes, in a dose dependent manner (Figs. 2 and 3).

It should be noted that bLF in the same dose inhibits the keratinocyte proliferation much more actively than stimulates the proliferation of dermal fibroblasts. So, at a dose of $200 \mathrm{mg} / \mathrm{ml}$ the cell proliferation in test samples decreased by more than 2 -fold compared with the control. There has also been found the effect of calf serum due to its components stimulating the cell growth that levels the bLF influence.

Thus, the reaction of the cells to bLF with regard to the growth properties may be either positive or negative. The immortalized keratinocytes are obvious to be considered as targets in a model bLF system to study the inhibiting cell growth mechanism. As regards fibroblasts, the degree of the bLF effect that stimulates their growth is not enough to deal with these cells as a component of the model, designed to study the molecular mechanism of bLF action as a growth factor.

With reference of the practical significance of probiotics as representatives of beneficial microflora in the gastrointestinal tract (GIT), developing the screening methods to find bLF sensitive strains is relevant. It is also necessary to establish adequate models in the study of mechanisms of the cell growth reactions to bLF and its derivatives. In particular, this method can be based on the binding of bLF to the cell surface. The activation of probiotic cells by bLF has been found to correlate with its binding to the cell surface.

In the study of the receptor mechanism, one of the industrially important strains of bifidobacteria Bifidobacterium adolescentis B-1 (deposited at the State Research Institute of Genetics and Selection of Industrial

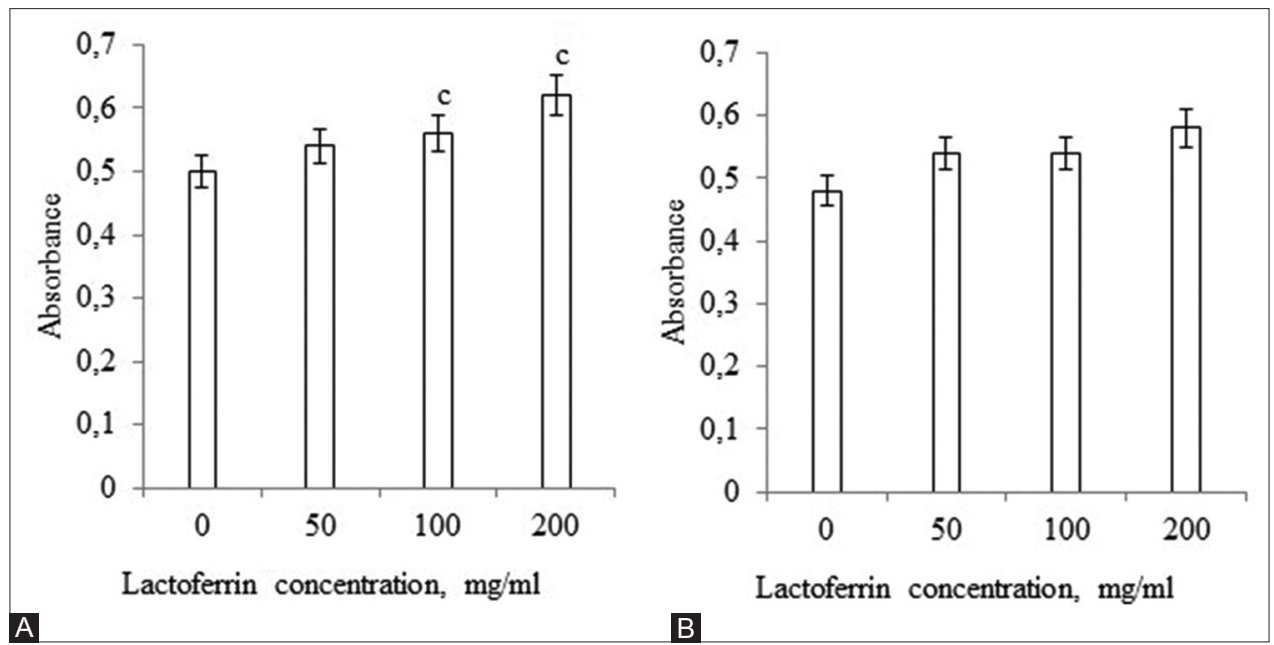

Fig 2. Effect of bovine lactoferrin on proliferation of postnatal human fibroblasts: (A) without the Fetal Bovine Serum; (B) with the Fetal Bovine Serum (10\%). ${ }^{c} P<0.05$ (in comparison with control).

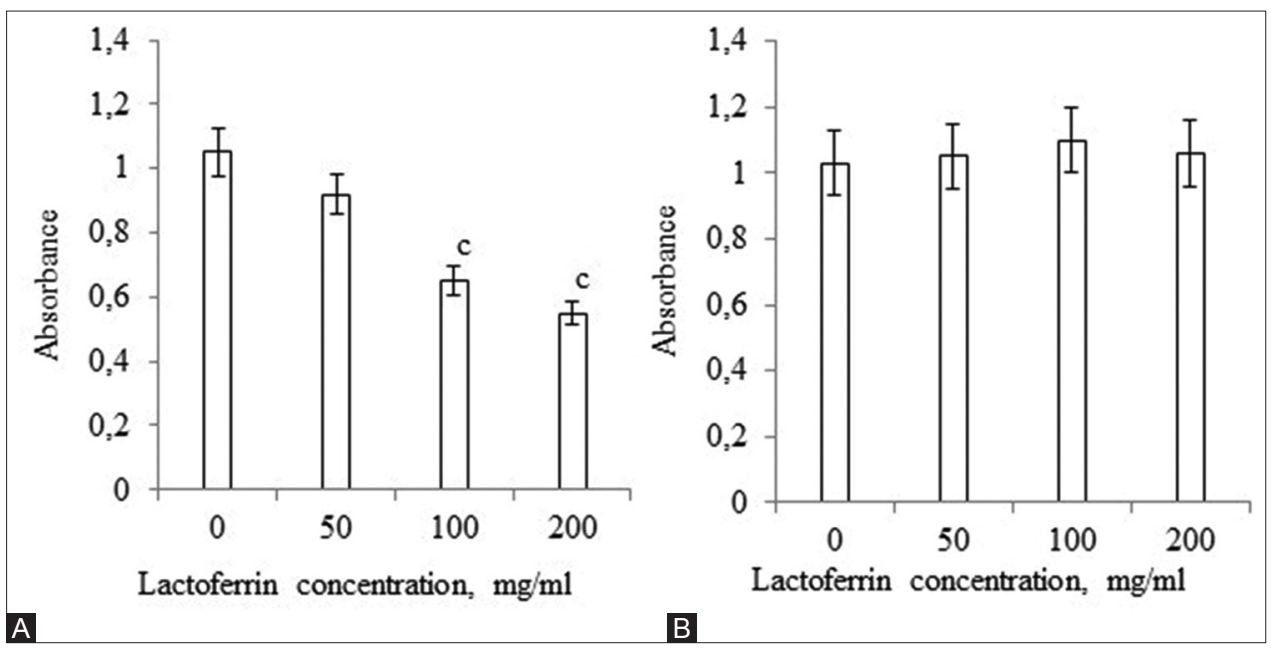

Fig 3. Effect of bovine lactoferrin on proliferation of immortalized human keratinocyte of HaCat line: (A) without the Fetal Bovine Serum; B) with the Fetal Bovine Serum (10\%). ${ }^{c} P<0.05$ (in comparison with control). 
Microorganisms, Russia, in the Russian National Collection of Industrial Microorganisms - RNCIM - № AC-1243) was adopted as the main component of the model system "cell-bLF". The microorganism selected is activated by bLF regardless of the ferric iron content in its molecule, but the effect was dose-dependent (Fig. 4).

Already during the first hours of peptic proteolysis, accumulation of bLF peptides with a molecular weight of about $3 \mathrm{kDa}$ was observed in the reaction mixture, with low molecular weight peptides mainly to cleave at the $\mathrm{N}$ - end of the molecule and to be represented by lactoferricins having high antimicrobial activity (Tomita et al., 1991; Ripolles et al., 2015). Further, the B. adolescentis B-1 peptides isolated from membrane were analyzed by electrophoresis, whereby their molecular weight was found to range 45-100 $\mathrm{kDa}$. The results of Westernblotting showed the native bLF to communicate with only one protein. Its molecular weight is about $58 \mathrm{kDa}$. It is noteworthy that the binding ability of the receptor protein toward the bLF protein substances labeled with LP correlates with their biological activity including the activation of bifidobacteria proliferation. Not sensitive to bLF strains of bifidobacteria also appeared to be inert toward its peptides that may indicate the possibility of implementing the effect on the cellular target of bLF and the products of its limited proteolysis through a single receptor mechanism, which may be a receptor one.

In the GIT, proteins are known to break down into oligopeptides, peptides, individual amino acids under the influence of proteolytic enzymes. Whey proteins of milk, including bLF, are relatively resistant to proteolysis, and products of their limited proteolysis are not only biologically active, but often, exhibit higher activity as compared to the native protein. So, the hydrolysates produced are more active than the original native bLF by different biological properties, with the activity of the peptides obtained at proteolysis of different duration with respect to the biological parameters under study to vary considerably. A significant excess of activity in terms of the growth index B. adolescentis B-1, as compared to the native bLF, was registered for peptides after 4 hours of proteolysis. Thus, the effect found is dosedependent in the concentration range of $50-250 \mu \mathrm{g} / \mathrm{ml}$. At the same time, the molecular mechanism of biological action including all the variety of effects of multifunctional products of the bLF proteolysis has been little investigated.

There is also reason to suppose that the effects of bLF and its peptides making themselves evident at the molecular and cellular levels underlay the mechanism of their physiological action in living organisms. Our in vivo studies have shown that peptides of bLF that are most active with regard to stimulating the bifidogenic ability of beneficial microorganisms proved to be more effective for the protection of the GIT from ulcer lesions of the gastric mucosa and dysbiosis.

So, a mixture of ethyl alcohol with hydrochloric acid was injected into the stomach of the laboratory rats that resulted in ulcer lesions to the mucosa formed (Fig. $5 \mathrm{~A}$ and $\mathrm{B}$ ). If 30 minutes before injecting the mixture into the stomach we introduced bLF and its hydrolyzates as compounds of normal saline, the ulcer lesions were less pronounced or absent (Fig. $5 \mathrm{C}$ and D). Hydrolysates were determined to be a more effective preventative than the native protein. The minimum dose ( $1 \mathrm{mg}$ per $1 \mathrm{~kg}$ of the animal body weight), the mucosal ulcerous erosion was not diagnosed as a result of injecting the mixture, was $300 \mathrm{mg}$ for bLF, $100 \mathrm{mg}$ for hydrolysates (after 4 hours of proteolysis), and $\sim 10 \mathrm{mg}$ (after 24 hours of proteolysis).

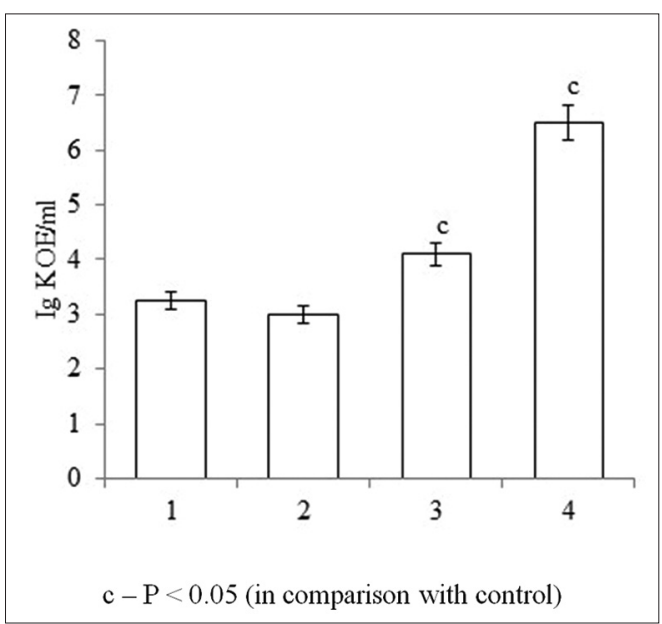

Fig 4. Effect of bovine lactoferrin on the growth of Bifidobacterium adolescentis B-1 under anaerobic conditions at $37^{\circ} \mathrm{C}$ for 48 hours in medium thioglycolic. Doses of bovine lactoferrin: $1-0 \mu \mathrm{g} / \mathrm{ml}$ (control); 2 - $50 \mu \mathrm{g} / \mathrm{ml} ; 3$ - $100 \mu \mathrm{g} / \mathrm{ml} ; 4$ - $300 \mu \mathrm{g} / \mathrm{ml}$.

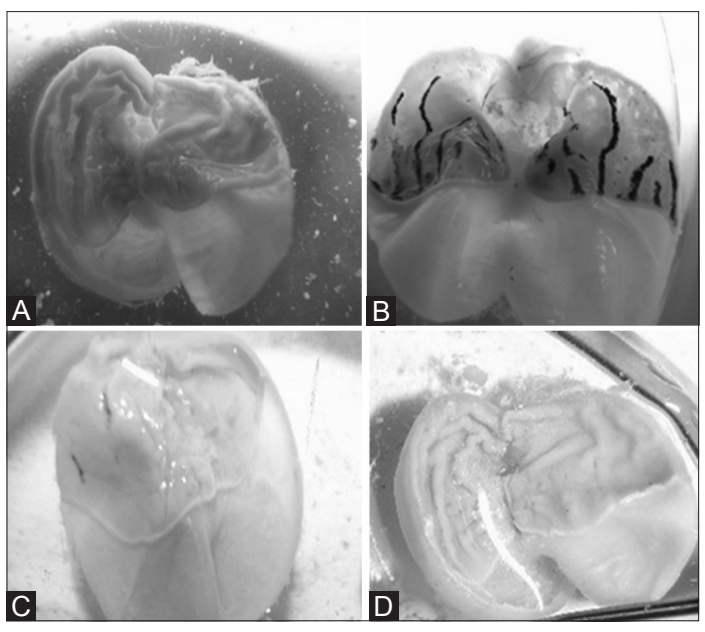

Fig 5. Gastric mucosa of rats: (A) norm; (B) 60 min after injection of the mixture inducing ulcer lesions; (C) bLF was introduced 30 minutes before injecting the mixture; (D) bLF hydrolyzates was introduced 30 minutes before injecting the mixture. 
At the oral supplementation, the peptides of low molecular weight had more pronounced antidysbiosis effect than the native bLF in the same concentration, which corresponds to the data obtained on the biological activity of bLF hydrolysates against pathogenic and beneficial gastrointestinal microflora.

\section{CONCLUSION}

The bLF in the same dose inhibits the keratinocyte proliferation much more actively than stimulates the proliferation of dermal fibroblasts. The binding ability of the receptor protein toward the bLF protein substances labeled with LP correlates with their biological activity including the activation of bifidobacteria proliferation. Not sensitive to bLF strains of bifidobacteria also appeared to be inert toward its peptides that may indicate the possibility of implementing the effect on the cellular target of bLF and the products of its limited proteolysis through a single receptor mechanism, which may be a receptor one. The peptides of bLF that are most active with regard to stimulating the bifidogenic ability of beneficial microorganisms proved to be more effective for the protection of the GIT from ulcer lesions of the gastric mucosa and dysbiosis.

\section{ACKNOWLEDGEMENTS}

The authors would like to express their great appreciation to the Russian Science Foundation for the financial support in the implementation of this research according to the scientific project \# 15-16-10000, NIIMMP.

\section{Authors contributions}

Study conception and design: Evgeniy Ivanovich Titov, Natali Aleksandrovna Tikhomirova, Ivan Fiodorovich Gorlov.

Measurements, Acquisition and Analysis of data: Inna Isaakovna Ionova.

Interpretation of data and Drafting of manuscript: Marina Ivanovna Slozhenkina, Natali Ivanovna Mosolova, Elena Yurievna Zlobina.

Critical revision: Ivan Fiodorovich Gorlov, Marina Ivanovna Slozhenkina, Natali Ivanovna Mosolova.

\section{REFERENCES}

Committee for the Update of the Guide for the Care and Use of Laboratory Animals; Institute for Laboratory Animal Research (ILAR); Division on Earth and Life Studies (DELS); National Research Council of the National Academies. 2011. Guide for the Care and Use of Laboratory Animals, $8^{\text {th }}$ ed. Washington, DC, USA: The National Academies Press.
Council for International Organizations of Medical Sciences. (1985) International Guiding Principles for Biomedical Research Involving Animals, Geneva, Switzerland: CIOMS.

Fotschki, J., A. Szyc and B. Wróblewska. 2015. Immunoreactivity of lactic acid-treated mare's milk after simulated digestion. J. Dairy Res. 82: 78-85.

García-Tejedor, A., M. Castelló-Ruiz, J. V. Gimeno-Alcañíz, P. Manzanares and J. B. Salom. 2015a. In vivo antihypertensive mechanism of lactoferrin-derived peptides: Reversion of angiotensin I-and angiotensin II-induced hypertension in wistar rats. J. Funct. Foods. 15: 294-300.

García-Tejedor, A., J. V. Gimeno-Alcañíz, S. Tavárez, E. Alonso, J. B. Salom and P. Manzanares. 2015b. An antihypertensive lactoferrin hydrolysate inhibits angiotensin I-converting enzyme, modifies expression of hypertension-related genes and enhances nitric oxide production in cultured human endothelial cells. J. Funct. Foods. 12: 45-54.

Hayakawa, T., C. X. Jin, S. B. Ko, M. Kitagawa and H. Ishiguro. 2009. Lactoferrin in gastrointestinal disease. Int. Med. 48: 1251-1254.

Jenssen, H. and R. E. Hancock. 2009. Antimicrobial properties of lactoferrin. Biochimie. 91: 19-29.

Ke, C., Z. Lan, L. Hua, Z. Ying, X. Humina, S. Jia, T. Weizheng, Y. Ping, C. Lingying and M. Meng. 2015. Iron metabolism in infants: Influence of bovine lactoferrin from iron-fortified formula. Nutrition. 31: 304-309.

Khramtsov, A. G. 2010. Adapting the doctrines of nanomembrane technologies based on whey clusters (Adaptatsiia doktrini nanomembrannikh tekhnologii na osnove klasterov molochnoi sivorotki). Dairy Industry (Molochnaia Promishlennost'). 1: 34-37.

Khramtsov, A. G. 2015. Innovative Priorities and Practices of Technology Platform of Modernization of the Dairy Industry in Russian Agriculture: Monograph. Voronezh Russia: Voronezh State Agrarian University Publishing House.

Kim, W. S., M. Ohashi, T. Tanaka, H. Kumura, G. Y. Kim, I. K. Kwon, J. S. Goh and K. Shimazaki. 2004. Growth-promoting effects of lactoferrin on $L$. acidophilus and Bifidobacterium spp. Biometals. 17: 279-283.

Laemmli, U. K. 1970. Cleavage of structural proteins during the assembly of the head of Bacteriophage T4. Nature. 227: 680-685.

Legrand, D., A. Pierce, E. Elass, M. Carpentier, C. Mariller and J. Mazurier. 2008. Lactoferrin structure and functions. Adv. Exp. Med. Biol. 606: 163-194.

Di Mario, F., G. Aragona, N. Dal Bò, G. M. Cavestro, L. Cavallaro, V. Iori, G. Comparato, G. Leandro, A. Pilotto, A. Franzè. 2003. Use of bovine lactoferrin for Helicobacter pylori eradication. Dig. Liver Dis. 35: 706-710.

Montiel, R., I. Martín-Cabrejas and M. Medina. 2015. Reuterin, lactoperoxidase, lactoferrin and high hydrostatic pressure on the inactivation of food-borne pathogens in cooked ham. Food Control. 51: 122-128.

Okuda, M., T. Nakazawa, K. Yamauchi, E. Miyashiro, R. Koizumi, M. Booka, S. Teraguchi, Y. Tamura, N. Yoshikawa, Y. Adachi and I. Imoto. 2005. Bovine lactoferrin is effective to suppress Helicobacter pylori colonization in the human stomach: A randomized, doubleblind, placebo-controlled study. J. Infect. Chemother. 11: 265-269.

Rahman, M. M., W. S. Kim, T. Ito, H. Kumura and K. Shimazaki. 2008. Examination of bovine lactoferrin binding to bifidobacteria. Appl. Biochem. Microbiol. (Prikladnaia biokhimiia i mikrobiologiia). 44: 529-532.

Rahman, M. M., W. S. Kim, T. Ito, H. Kumura and K. Shimazaki. 2009. 
Growth promotion and cell binding ability of bovine lactoferrin to Bifidobacterium longum. Anaerobe. 15: 133-137.

Ripolles, D., S. Harouna, J. A. Parrón, M. Calvo, M. D. Pérez, J. J. Carramiñana and L. Sánchez. 2015. Antibacterial activity of bovine milk lactoferrin and its hydrolysates prepared with pepsin, chymosin and microbial rennet against foodborne pathogen Listeria monocytogenes. Int. Dairy J. 45: 15-22.

Sachdeva, A. and J. Nagpal. 2009. Meta-analysis: Efficacy of bovine lactoferrin in Helicobacter pylori eradication. Aliment. Pharmacol. Ther. 29: 720-730.

Shimazaki, K., T. Tazume, K. Uji, M. Tanaka, H. Kumura, K. Mikawa and T. Shimo-Oka. 1998. Properties of a heparin-binding peptide derived from bovine lactoferrin. J. Dairy Sci. 81: 2841-2849.

Shimazaki, K. 2000. Lactoferrin: A marvelous protein in milk? Anim. Sci. J. 71:329-347.

Tomita, M., W. Bellamy, M. Takase, K. Yamauchi, H. Wakabayashi and K. Kawase. 1991. Potent antibacterial peptides generated by pepsin digestion of bovine lactoferrin. J. Dairy Sci. 74: $4137-$ 4142.

Tomita, M., H. Wakabayashi, K. Shin, K. Yamau-chi, T. Yaeshima and K. Iwatsuki. 2009. Twenty-five years of research on bovine lactoferrin applications. Biochimie. 91: 52-57.

Yamauchi, K., H. Wakabayashi, K. Shin and M. Takase. 2006. Bovine lactoferrin: Benefits and mechanism of action against infections. Biochem. Cell Biol. 84: 291-296.

Yoo, Y. C., S. Watanabe, R. Watanabe, K. Hata, K. Shimazaki and I. Azuma. 1997. Bovine lactoferrin and lactoferricin, a peptide derived from bovine lactoferrin, inhibit tumor metastasis in mice. Jpn. J. Cancer Res. 88: 184-190.

Zhao, J. M., J. W. Wang, R. J. Meng, M. B. Fu, H. M. Wang, B. Tang, M. Chen and N. Li. 2015. Development of pilot purification procedure and analysis of activity of recombinant human lactoferrin from milk of transgenic cattle. Zhong Guo Sheng Wu Zhi Pin Xue Za Zhi. 28: 182-189. 